\title{
Turiyam Set a Fourth Dimension Data Representation
}

\author{
Prem Kumar Singh \\ Department of Computer Science and Engineering, Gandhi Institute of Technology and Management-Visakhapatnam, Andhra \\ Pradesh, India \\ Email: premsingh.csjm@gmail.com,premsingh.csjm@yahoo.com
}

How to cite this paper: Singh, P.K. (2021) Turiyam Set a Fourth Dimension Data Representation. Journal of Applied Mathematics and Physics, 9, 1821-1828. https://doi.org/10.4236/jamp.2021.97116

Received: April 13, 2021

Accepted: July 27, 2021

Published: July 30, 2021

\begin{abstract}
Recently most of the authors focused on dealing with uncertainty. To deal with that algebra of fuzzy sets is introduced in three-way fuzzy space. It gave way to characterize the attributes in true, false or uncertain regions. It is found in chemistry also as an electron, proton and neutron. The problem arises when the attributes are beyond the three-dimensions. One of suitable examples is winning, draw or loss of a match cannot define the win draw or loss of series. It is measured in international relationships also like USA-China, USA-Russia, India-Pakistan or Israel-Philistine. Some countries support the USA, some countries support China, some countries are neutral in hidden consciousness to fulfill their agenda. It is also measured in democratic countries like India where some people vote in favor of a party, some people vote against the given party, some people may be absent or walkout whereas some people vote NOTA. This last dimension is called as Turiyam or fourth dimension. This last dimension is influenced from Yin-Yang theory of Chinese Taoism as well as Sanskrit Yamma-Yammi and its complement. The Turiya means measuring each dimension in silent mode. There is less attention paid towards the necessity of fourth dimensions and its algebra. This paper will discuss gimbal lock of three-way fuzzy space using the Tuiyam set and its algebra.
\end{abstract}

\section{Keywords}

Fourth Dimensions, Plithogenic Set, Three-Way Decision Space, Turiyam Set, Granulation

\section{Introduction}

Recent time a method is proposed to deal with uncertainty in data using the three-way fuzzy space [1] [2] [3] [4]. In this case the categorization of uncer- 
tainty is done independently using truth, falsity, and indeterminacy of neutrosophic set [5] [6] [7] [8]. The problem arises while dealing with refusal degree. The Plithogenic set also just try to consider it as contradiction rather than a new dimension. This paper tied to deal with gimbal lock of three way dimensions and its representation as shown in Figure 1.

It can be observed that a coin shown in Figure 1 is gimbal lock can move in any of way (up/down, left/right and front/back) but cannot escape. Just drag it and kept it in fourth dimension the coin can be easily left without changing its co-ordinates in three-dimensional spaces. It used to observed at time when a mother pregnant [9] [10]. It means mother realizes fourth dimensions i.e. Turiyam set of child its awake, sleep and dream at given phase. Another example is voting system in democratic country like India where some people vote in favor of a party $(t)$, some people vote against the party $(f)$, some people used to absent due to some unavoidable reason (I), some people vote None of the Above i.e. NOTA (I). These are the people who vote in conscious mind that none of the leader is good at the time without harming anyone. Recently, it became hot topic when many activists went to Supreme Court to deal with NOTA vote [11]. This type of information cannot be written precisely in three-way fuzzy space. Similarly, for medical diagnoses data set there are four conditions which arise the medicine is effective, medicine is ineffective, medicine is destructive or medicine has allergies with the given patients.

To deal with above data set the current paper introduced Turiyam set and its basic algebra. It is motivated from Sanskrit word turiya i.e. chaturiya state as pure consciousness [12] [13]. It means turiyam is beyond all these three states i.e. acceptation, rejection and uncertain. It can be also measured as the state of liberation means experiencing the infinite (ananta) and non-different (advaita/abheda) from all the experiences as Love (or Loyalty) which makes awake in each external dimension. It is Turiya state where the foundational of self is realized based on its true, false or uncertain act. Turiyam means emotional communication with our heart [14]. The processes of understanding social assassination fear or loyalty of an employee is called as Turiyam or fourth dimensions. It is beyond the true, false or uncertain act. It is measureless, neither cause nor effect, all pervading, without suffering, blissful, changeless, self-luminous, real, immanent in all things and transcendent like Judgement. Turiyam has a direction as

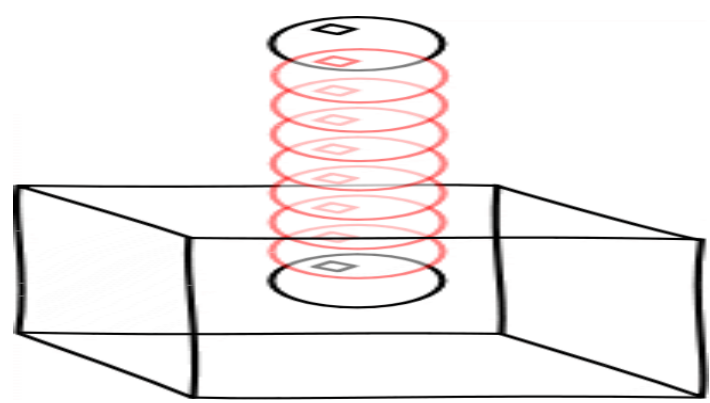

Figure 1. A precise example for need of Turiyam set. 
well as measurement due to which current paper focuses on mathematical algebra of turiyam is introduced first time as set [15] as many-valued logic [16] [17]. As for example the Human being used to measure all his/her activities true, false, neutral activities including the growth of each part of his/her body using eyes [18] as cat can observe 9-dimensions [19]. The eyes validates the truth, false, indeterminacy of activity based on time is called as Turiyam [20] [21]. However the blind people validate of feel the three-dimension as Tuiyam. The activity of blind people can be written in form of Tuiyam set to understand their cognition. The turiyam set have Up-Down $(x)$, Left-Right $(y)$, Back-Forth $(z)$ and Turiyam $(w)$ as Fourth dimension [22] which can be observed recently using other mathematics also in different format [23] [24] [25]. This paper focused on introducing this new dimension Fourth State as Turiyam state can be considered as Liberal or Turiyam Set.

Rest part of the paper is organized as follows: Section 2 contains algebra of turiyam set and its introduction. Section 3 provides illustrative example of the $\mathrm{Tu}$ riyam set and its application with comparative analysis. Section 4 includes conclusions followed by references.

\section{Turiyam Set and Its Algebra}

In this section the concept of Turiyam graph and its necessity is established by connection with third dimensions as follows:

Definition 1: Neutrosophic Set [4] [5]: This set was introduced to handle the uncertainty based on three independent functions called as truth, indeterminacy and false, $(T, I, F)$ as mutually exclusive under the conditions $0^{-} \leq T+I+F \leq 3^{+}$ in form of a set:

$N=\left\{\left\langle k ; T_{N}(k), I_{N}(k), F_{N}(k)\right\rangle: k \in \xi ; T_{N}(k), I_{N}(k), F_{N}(k) \in \xi\right]^{-} 0,1^{+}[\}$as shown in Figure 2 .

Problem 1 (Three-dimension): Let us suppose someone wants to enter a dot (.) into the Figure 1 without cutting the cubes lines. It is not possible in three-dimensions. One has to extend the dimension to come out from gimbal lock of three dimensions. One of the suitable examples is mother kept the child in her womb till 9 months in three-dimension cube as shown in Figure 2. It is like a sphere sitting in fourth dimension as sphere sitting in Four dimension as $t^{2}$ $+i^{2}+f^{2}+P=1$. The mother measures awake, sleep and deep sleep condition of

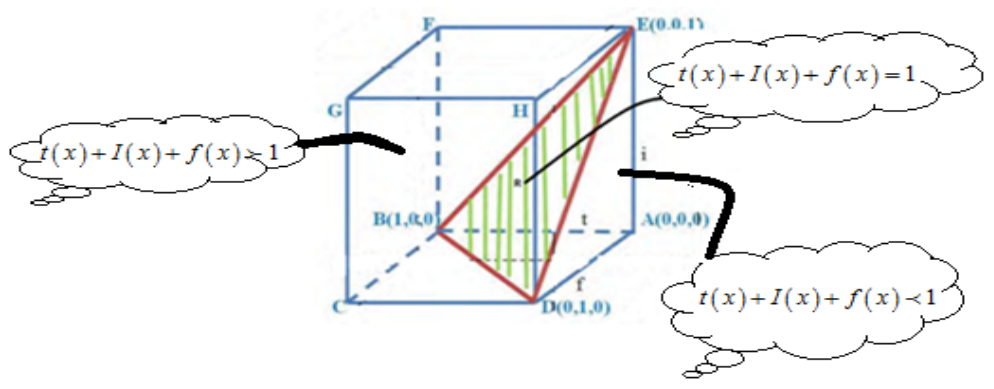

Figure 2. The three-way space representation using Neutrosophic set. 
child in cube as Turiyam state. In this case mother realizes fourth dimensions till the 9 months.

Problem 2 (Physics): A problems which gives motivation of Turiyam or fourth dimensions like in case two rings connected with each other in three dimensional spaces. Is it possible to separate them without other independent dimension?

Problem 3 (Conscious): The concept of Turiyam set is beyond the truth, false, uncertainty of Neutrosophic values. It can be understood using the NOTA. It is liberal state and not the hesitant part of the Neutrosophic set i.e. $(1-t-i-$ f). Indian Veda also says that there are four dimension of awake. The first is "Vaisva" that represents the realization of world in the awake state (Jaagrat). The second is "Taijasa" that represents realization of world dream state (Swapna). The third is "Praajna" that is total non-awareness means deep sleep (Sushupti). These three states are defines the concept of uncertainty exists or not-exists in the realization. The fourth stage is called as "Turiyam", which is the awareness of non-awareness of the absolute unimaginable can be called as liberalization.

Definition 2 (Representation of Turiyam): Turiyam is truth which is beyond three dimensions. The three-dimension can be visualized as cross section of Turiyam. It changes based on time can be noted mathematically as:

1) The first state is the waking state, in which we are aware of our daily world can be denoted as $(t)$.

2) The second state is the dreaming state can be denoted $(f)$.

3) The third state is the state of deep sleep $(i)$.

4) Turiyam as Liberal State $(I)$.

It can be measured as mother who sees all the state of a child in her womb like awake, sleep or dram. The fourth state is liberalization of child as the doctrine of temporal parts. It can be considered as ontological position that an object's persistence through time is like its extension as another dimensions. Turiyam Set can contain 4-tuple: truth $(t)$, Indeterminacy $(I)$, falsity $(f)$, and liberalization $(I)$. Each of the dimensions is independent to each other as: $0 \leq t+i+f+l \leq 4$. The turiyam value 0 represents the universal neutral values, -4 represents universal false cases and +4 represent the universal truth cases i.e. $T=\{\langle x: t, i, f, l\rangle: x \in \xi\}$. It means this set contains a true, a false, an indeterminacy membership values and a liberalization values which can be characterized independently as.

$$
T=\left\{\left\langle k ; t_{t}(k), I_{t}(k), F_{t}(k), l_{t}(k)\right\rangle: k \in \xi\right\}
$$

where $0^{-} \leq t(k)+I_{t}(k)+f_{t}(k)+l_{t}(k) \leq 4^{+} \quad$ (Figure 3).
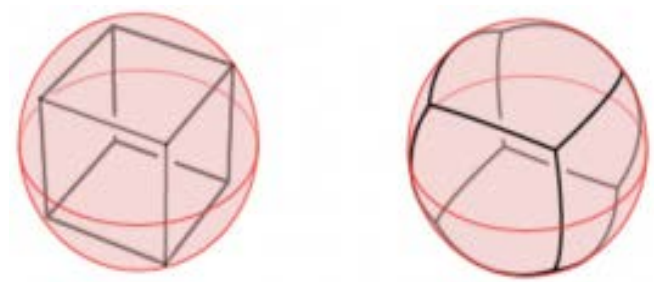

Figure 3. The Turiyam visualization of three-dimensions. 
Definition 3 (Intersection of Turiyam): The intersection of turiyam set $T_{1}$ and $T_{2}$ can be computed as follows:

1) $T_{1} \wedge T_{2}=\left(\left(t_{1} \wedge t_{2}\right),\left(i_{1} \vee i_{2}\right),\left(f_{1} \vee f_{2}\right),\left(l_{1} \wedge l_{2}\right)\right)$.

2) $T_{1} \wedge T_{2}=\left(t_{1} \cdot t_{2}, i_{1}+i_{2}-i_{1} \cdot i_{2}, f_{1}+f_{2}-f_{1} \cdot f_{2}, l_{1} \cdot l_{2}\right)$.

It will helpful in finding the maximum common opinion in two intellectuals and their conversations.

Definition 4 (Union of Turiyam): The union of turiyam set $T_{1}$ and $T_{2}$ can be computed as follows:

1) $T_{1} \vee T_{2}=\left(\left(t_{1} \vee t_{2}\right),\left(i_{1} \wedge i_{2}\right),\left(f_{1} \wedge f_{2}\right),\left(l_{1} \vee l_{2}\right)\right)$.

2) $T_{1} \vee T_{2}=\left(t_{1}+t_{2}-t_{1} \cdot t_{2}, i_{1}, i_{2}, f_{1} \cdot f_{2}, l_{1}+l_{2}-l_{1} \cdot l_{2}\right)$.

It will helpful in finding that two intellectual of different era or space are once agree on a given thought.

Definition 5 (Complement of Turiyam): The complement of turiyam set can be computed as follows:

$$
t^{\prime}=f, i^{\prime}=1-i, f=t, l^{\prime}=1-(t+i+f)
$$

It will helpful in finding the refusal degree of two intellectual based on given thought.

It means the complements of Turiyam is independent and provide maximum values of non-refusal.

Definition 6 (n-refinement of Turiyam): In case the refusal measurement become uncertain then the turiyam set can be written as $0 \leq t+i_{1}+f+i_{2} \leq 4$ that is refinement of $\mathrm{n}$-valued Neutrosophic set. In this way, the turiyam can be written in form of refinement as follows: $0 \leq \sum t+\sum i+\sum f+\sum l \leq n$ to handle the $n$-finite truth, uncertain, false, and liberalization to measure the $n$-number of elements.

In this way, turiyam set allow to measure the universal false, universal true, universal neutral cases other than that are uncertain cases which can be analyzed based on time. The turiyam set have Up-Down or length $(x)$, Left-Right or width $(y)$, Back-Forth or height $(z)$ and Trench or Turiyam $(w)$ as shown in Figure 3. These can be written using the vertices of square $(1,1,1,1),(1,1,-1,1),(1,1$, $-1,-1)$, and $(1,1,1,-1)$. It means the turiyam set must have at least one element which measurement of changes is either 0 or undefined as Trinition [23] or Quaternions [24]. In the next section an example is given for data with Turiyam attribute with illustration.

\section{Data with Turiyam Attributes}

Recently, many multi-level attributes contains the attributes beyond third dimensions. One of the suitable example is voting system where in democratic country like India where some people vote in favor of a party $(t)$, some people vote against the party $(f)$, some people used to absent due to some unavoidable reason (I), some people vote None of the Above i.e. NOTA (I). These are the people who vote in conscious mind that none of the leader is good at the time without harming anyone. Recently, it became hot topic when many activists 
went to Supreme Court to deal with NOTA vote. This type of information can be written precisely using the Turiya set. The people who refused to vote can be investigated using $1-(t+i+f+I)$. In this way, the turiyam set established a way to deal with data having four independent dimensions. It can be easily represented using Turiyam context as shown in Table 1 for knowledge processing task.

There are other examples of data with Turiyam attributes as follows:

Example 2: (Cricket Data) The cricket data sets contain Turiyam attributes. It is convicted in many matches that India used to loss a match just to stop the Pakistan in a tournament and vice versa. It means the win, draw or loss of match is based on partial fulfillment of some agenda like win of series. One of the example win, draw or loss percentages cannot say precisely that how many series a team has won. It may happen that, some team has won many matches but did not win many Test series and vice versa. It means the win, draw or loss of match is nothing but cross section of the fourth dimensions. This fourth dimension is called as Turiyam.

Example 3: (Cognitive Science) Let us suppose that, 3 person kept in 3 different dark room for psychological cognitive test. The psychological traverse a thick rope in the dark room from upper side. It may happen that person says that it is snake, some person says that not snake, some may say it is uncertain. However the Turiyam is it is just rope. Let us suppose that a person says that it looks 70 percent snake and 30 percent is unclear. It can be represented as $(0.7,0.0,0.3,0)$. In similar way other opinion can be written.

Example 4: (Chemistry) The chemistry reports electron, proton, neutron and another atom positron to deal with z-matrix. The positron is Turiya attribute.

Example 5: (Crime Data) It is discussed several times that many Indian girls or boy donot report for any sexual incidence happened to them due to fear of social discrimination, due to fear or losing the family reputation, or other political reasons. It may happen that it is positive, negative or uncertain but the girls or boys used to hide this truth in mind. This type of human cognition is Turiya state and dimension which keeps liberal in each state. How to deal with this type of attributes is a major task. The reason is these types of data used to find in dark data set which collection and preprocessing takes lot of time. To achieve this goal, the Turiya set will be helpful.

Example 6: (Journal Data) A journal paper is good does not depend that, the journal has impact factor, journal do not have impact factor, uncertain that

Table 1. A fourth dimension or Turiyam context.

\begin{tabular}{|c|c|c|c|c|}
\hline & $A_{1}$ & $A_{2}$ & $\cdots$ & $A_{\mathrm{m}}$ \\
\hline$O_{1}$ & $R_{11}\left(t_{11}, i_{11}, f_{11}, l_{11}\right)$ & $R_{12}\left(t_{12}, i_{12}, f_{12}, l_{12}\right)$ & $\ldots$ & $R_{1 \mathrm{~m}}\left(t_{l m}, i_{l m}, f_{l m}, I_{l m}\right)$ \\
\hline $\mathrm{O}_{2}$ & $R_{21}\left(t_{21}, i_{21}, f_{21}, I_{21}\right)$ & $R_{22}\left(t_{22}, i_{22}, f_{22}, 1_{22}\right)$ & $\cdots$ & $R_{23}\left(t_{2 m}, i_{2 m}, f_{2 m}, l_{2 m}\right)$ \\
\hline$\cdots$ & & & & \\
\hline$O_{n}$ & $R_{n l}\left(t_{n l}, i_{n l}, f_{n l}, I_{n l}\right)$ & $R_{n 2}\left(t_{n 2}, i_{n 2}, f_{n 2}, I_{n 2}\right)$ & $\ldots$ & $R_{\mathrm{nm}}\left(t_{n m}, i_{n m}, f_{n m}, I_{n m}\right)$ \\
\hline
\end{tabular}


journal will receive impact factor. Similarly, it does not depends on that, Journal is indexed in web of science, does not indexed in web of science or may be uncertain about its indexing in web of science. There are many Journals which are good without impact factor or without Web of Science Indexed. It means the quality of journal is beyond these three-regions. The researchers of particular areas know by his/her consciousness that this Journal is good or not. This last dimension is called as Turiyam where less attention has been paid. The reason is analysis of this type of Turiyam attributes dark data and its collection required. Same time author can find those journals where he/she do not submit the paper due to conflict of interest. It can be easily find using refusal degree of Turiyam set as $1-1-(t+i+f+1)$.

Example 7: (Medical Data) the turiyam set can be useful to deal with medical diagnoses data sets. Let us suppose, a doctor gives medicine to some patient for controlling the given disease. The medicine will be highly effective, the medicine will be partially effective, the medicine will be badly effective, or the medicine will be effective or destructive does not known to doctor. This type of data set can be easily written via Turiyam set. Same time the doctor can classify that these type of medicines should not be given to particular patients due to allergy. It can be easily found using the refusal degree as: $1-(t+i+f+1)$.

In this way turiyam set precisely give a way to analyze the human cognition and its agenda. The proposed method will be helpful for various researchers to deal with knowledge processing tasks and understanding the human cognition.

\section{Conclusion}

This paper introduces Turiyam set and algebra to deal with gimbal lock of three-way fuzzy space with an illustrative example. In future, the author will focus on introducing graphical structure visualization of turiyam set.

\section{Funding}

Author declares that, there is no funding for this paper.

\section{Ethics Approval}

This article does not contain any studies with human or animals participants.

\section{Conflicts of Interest}

The author declares that he/she has no conflict of interest.

\section{References}

[1] Singh, P.K. (2017) Three-Way Fuzzy Concept Lattice Representation Using Neutrosophic Set. International Journal of Machine Learning and Cybernetics, 8, 69-79. https://doi.org/10.1007/s13042-016-0585-0

[2] Singh, P.K. (2018) Three-Way N-Valued Neutrosophic Concept Lattice at Different Granulation. International Journal of Machine Learning and Cybernetics, 9, 1839-1855. https://doi.org/10.1007/s13042-018-0860-3 
[3] Singh, P.K. (2020) Plithogenic Set for Multi-Variable Data Analysis. International Journal of Neutrosophic Sciences, 1, 81-89.

[4] Smarandache, F. (1995) Neutrosophy, Neutrosophic Theories and Applications. http://fs.gallup.unm.edu/neutrosophy.htm

[5] Smarandache, F. (1998) Neutrosophy. Neutrosophic Probability, Set, and Logic. ProQuest Information and Learning. Ann Arbor, Michigan, USA.

[6] Smarandache, F. (2013) N-Valued Refine Neutrosophic Logic and Its Applications to Physics. Progress in Physics, 4, 143-146.

[7] Smarandache, F. (2017) Plithogeny, Plithogenic Set, Logic, Probability, and Statistics. Pons Publishing House, Brussels.

[8] Smarandache, F. (2018) Extension of Soft Set to hyperSoft Set, and Then to Plithogenic Hypersoft Set. Neutrosophic Set and System, 22, 168-170.

[9] https://www.tribuneindia.com/news/archive/lifestyle/turiya-the-fourth-dimensionof-being-448113

[10] https://en.wikipedia.org/wiki/Turiya

[11] https://en.wikipedia.org/wiki/Four-dimensional space

[12] http://yogananda.com.au/g/g turiya.html

[13] https://sreenivasaraos.com/tag/turiya/

[14] https://en.wikipedia.org/wiki/None of the above

[15] https://www.speakingtree.in/blog/significance-of-mounam-or-silence

[16] https://en.wikipedia.org/wiki/Many-valued logic

[17] https://www.pitt.edu/ jdnorton/teaching/HPS 0410/chapters/four dimensions/ind ex.html

[18] https://researchblog.duke.edu/2017/04/26/visualizing-the-fourth-dimension/

[19] https://cleverpetowners.com/can-cats-see-all-9-dimensions/

[20] Williams, K.L. (2008) Understanding Om (Aum), Turiya, and the Three States of Consciousness in the Māndūkya Upanisad. Psycholoical Perpectives, 51, 287-315. https://doi.org/10.1080/00332920802457760

[21] Srinivasan, N. (2020) Consciousness without Content: A Look at Evidence and Prospects. Front. Psychology, 11, 1992. https://doi.org/10.3389/fpsyg.2020.01992

[22] Lawrence, S. (2015) Life, Architecture, Mathematics and Fourth Dimensions. Nexus Network Journal, 17, 587-604. https://doi.org/10.1007/s00004-014-0221-9

[23] Atangana, A. and Mekkaoui, T. (2019) Trinition the Complex Number with Two Imaginary Parts: Fractal, Chaos and Fractional Calculus. Chaos Solitions and Fractals, 128, 366-381. https://doi.org/10.1016/j.chaos.2019.08.018

[24] Ippoliti, E. (2019) Heuristics and Inferential Microstructures: The Path to Quaternions. Foundations of Science, 24, 411-425. https://doi.org/10.1007/s10699-018-9576-9

[25] Banchoff, T. (2008) Shadows of Reality: The Fourth Dimension in Relativity, Cubism, and Modern Thought. The Mathematical Intelligencer, 30, 74-75. https://doi.org/10.1007/BF02985763 